\title{
Adolescent Pregnancy Risks in a City of Average Size in Northeastern Brazil
}

\section{Themístocles Soares de Magalhaes ${ }^{1}$, Milena Bastos Brito ${ }^{1 *}$, Maria Fernanda Rios Grassi ${ }^{1,2}$ and Marcos Almeida Matos ${ }^{1}$}

${ }^{1}$ Bahiana School of Medicine and Public Health, Science Development Foundation of Bahia, Salvador, Brazil

${ }^{2}$ Advanced Laboratory of Public Health (CPQGM), Oswaldo Cruz Foundation (FIOCRUZ), Salvador, Brazil

\begin{abstract}
Introduction: Pregnancy in adolescence is a frequent public health problem worldwide, because it is associated with increased clinical and social complications affecting both mothers and newborn/infants.

Materials and Method: An analytical prospective study was conducted, comparing 200 pregnant women followedup during pre-natal care in the city of Cruz das Almas-Bahia-Brazil, in the period between November, 2009 and October, 2010. Women were divided into two groups: adolescents (between 10 and 19 years old) and adults (between 20 and 36 years old). The following socio-demographic variables were analyzed: self-declared color, educational level, marital status, family income. The maternal clinical variables evaluated were: parity, gestational age, gynecological age, weight, height, number of pre-natal consultations, weight gain during pregnancy, mode of birth and complications at birth. The clinical variables described for the newborn were: prematurity, birth weight, Apgar Score in first and fifth minute post-birth.
\end{abstract}

Results: The socio-economic characteristics differed between the groups. Among adolescent group, there were more single women; family income was lower; first sexual intercourse took place earlier than adult group. There was no difference in maternal and newborn clinical outcomes between the groups, with exception of birth weight, which was lower in adolescent group than adult group.

Conclusion: Pregnancy in adolescence is associated with greater social vulnerability, and not with biologic risk when compared with pregnancy at adult age.

General Context: The results founded herein demonstrated that pregnancy in adolescence was not associated with unfavorable perinatal or obstetric results, but was associated with greater social vulnerability when compared with those of adult pregnant women.

Keywords: Teenage; Pregnancy; Complications; Prenatal care; Behavior; Adolescent

\section{Introduction}

Adolescence is a biologic process that occurs between 10 and 19 years of age. In this period, rapid physical and psychosocial changes occur, such a cognitive maturation, structuring of the personality and development of sexuality, with repercussions throughout life [1]. Teenage pregnancy is a problem worldwide. Every year around 900,000 adolescents fall pregnant in the United States. In spite of decreasing rates over the last few decades, over four in every 10 adolescents fall pregnant before 20 years of age [2]. It is known that $85 \%$ of pregnant adolescents are in developing countries, and $24 \%$ of all maternal deaths occur in this age-range [3]. In Brazil, although a decline in total fertility has been observed over the last decade, in the age group of under 20 years, fecundity has remained practically stable [4]. It is estimated that in this Country, one in every four pregnant women is adolescent, corresponding to $22 \%$ of the total number of pregnant women $[4,5]$. According to the Brazilian Institute of Geography and Statistics, in 2011, in Bahia, there were 46,620 (21.68\%) births among adolescents [4].

Teenage pregnancy is correlated to physical and psychosocial risks. From the point of view of maternal-fetal complications, a higher incidence has been observed of: premature birth [6], low birth weight (LBW) [7], maternal mortality [8], pre-eclampsia [9], anemia [9] and sexually transmitted diseases. The psychosocial problems of adolescent pregnancy include low educational level; persistent poverty, repeated pregnancy, absence of partner $[5,9,10]$.

Due to the concern of teenage pregnancy be considered a public health problem, the aim of the present study was to verify the hypothesis that pregnancy in adolescence present a high level of biologic and social risks for pregnant women and the newborn (NB) when compared with pregnancy at adult age, in a city of average size in the Brazilian Northeast, one of the least developed regions in the country [11].

\section{Materials and Methods}

An analytical prospective study was conducted, comparing 200 pregnant women followed-up during pre-natal care at public care units in the city of Cruz das Almas-Bahia: new Family Health Program posts, at the outpatients clinic of the Pediatric Institute of Recôncavo ("Instituto de Pediatria do Recôncavo") and at "Santa Casa de Misericórdia", in the period between November 2009 and October 2010. The women were divided into two groups: 100 adolescents (between 10 and 19 years old) and 100 adults (between 20 and 36 years old). The city of Cruz das Almas is located in the coastal region of the State of Bahia,

*Corresponding author: Milena Bastos Brito, Bahiana School of Medicine and Public Health, Science Development Foundation of Bahia, Salvador, Brazil, Tel: 71 3276 8265, Fax: 713276 8202; E-mail: milenabrito@bahiana.edu.br

Received: July 22, 2014; Accepted: October 29, 2014; Published: October 31 , 2014

Citation: de Magalhaes TS, Brito MB, Grassi MFR, Matos MA (2014) Adolescent Pregnancy Risks in a City of Average Size in Northeastern Brazil. J Preg Child Health 1: 120. doi:10.4172/2376-127X.1000120

Copyright: () 2014 de Magalhaes TS, et al.This is an open-access article distributed under the terms of the Creative Commons Attribution License, which permits unrestricted use, distribution, and reproduction in any medium, provided the original author and source are credited. 
has 58,606 inhabitants, of whom 30,924 (52.7\%) are of the female sex. In the general population, there are 5,095 adolescent women. Based on the years 2009 and 2010 , the total number of live births in the city of Cruz das Almas was 1801, with adolescents contribution to this number being 290 NB. From these data it is possible to estimate the rate of teenage pregnancy in the municipality was $16.1 \%$. The participants were sequentially included in the first pre-natal consultation, and were re-evaluated at the time of birth for evaluation of the outcomes of NB and mothers. The inclusion criteria were as follows: pregnant women between 10-36 years of age, as from the $12^{\text {th }}$ week of gestation, who sought care at the previously mentioned services. Women were excluded if they suffered from chronic pathologies before pregnancy, such as chronic hypertension, diabetes type 1 and 2 , systemic lupus erythematous.

The sample size was calculated for an alpha error ( $p$ ) equal to 0.05 and a sampling error of $10 \%$, taking into consideration a loss of $20 \%$ in the segment. The minimum " $n$ " obtained was 75 pregnant women for each study group. There were included more volunteers than needed 100 for adolescent group and 100 for adult group. The following sociodemographic variables were described: age, self-declared color, marital status (single, married, consensual relationship), family income (Brazilian minimum wages), educational level (years of formal education), and smoking. The maternal clinical variables evaluated were parity, gestational age in weeks, gynecological age (interval between menarche and date of first birth), weight (Kg), height (centimeters), number of pre-natal consultations, weight gain during pregnancy, mode of birth and complications at birth. The clinical variables described for the NBs were prematurity ( $<37$ weeks of gestational age), birth weight $(<2,500 \mathrm{~g}$, between 2,500 and 3,999 g, and $>4,000 \mathrm{~g})$, Apgar score [12] in the first and fifth minute post-birth.

The laboratory variables that routinely form part of the pre-natal care were also evaluated as follows: urine type 1, complete hemogram, fasting glycemia, blood group, Rh factor, serologies for syphilis, toxoplasmosis, rubella, HIV, HTLV and oncotic cytology. A monthly clinical-obstetric evaluation was performed, while the laboratory and ultrasound evaluations were performed at each trimester of gestation. The variables relative to the NB were obtained in the immediate postpartum period. The data of sociodemographic variables were described as mean and standard deviation. The qualitative variables were analyzed in proportions. The t-test was used to verify statistical differences for continuous variables, and the Chi-square test performed for qualitative variables. For statistical analyses the statistical software program SPSS 16.0 for Windows (SPSS Inc, v.13, Chicago, IL and USA) was used. The research protocol was approved by the Research Ethics Committee of the Bahian Foundation for the Development of Sciences in Salvador, Bahia (No. 326/2009). All the patients who agreed to participate in the study signed the Term of Free and Informed Consent.

\section{Results}

The mean age of adolescents was $17.15 \pm 1.66$ years versus $30.39 \pm$ 5.33 years for adult women. Nineteen percent of adolescents were the age of 16 years or less (Figure 1). Half of the adolescents were single (versus $30 \%$ of the adults, $\mathrm{p}<0.001$ ) and only $45 \%$ of them lived with a partner/husband (versus $72 \%$ in the group of adults, $p<0.001$ ). The pregnant teenagers also had a lower family income, of 1.23 minimum wages (versus 1.41 minimum wages in the group of adults, $\mathrm{p}=0.04$ ) (Table 1).

The ages at the time of beginning with sexual life and first pregnancy were lower among the adolescents when compared with the group of adults: $15.07 \pm 1.49$ years (versus $18.44 \pm 3.52$ years, $\mathrm{p}<0.001$ ) and $16.26 \pm 1.78$ years (versus $23.15 \pm 5.0$ years, $\mathrm{p}<0.001$ ) respectively. The gynecological age that corresponds to the number of years between the present age and age at menarche was also lower in the group of adolescents than in the group of adults $(3.54 \pm 1.66$ years versus $10.26 \pm 5.04$ years, $\mathrm{p}<0.001)$. Whereas the number of sexual partners did not differ between the groups (Table 2). Twelve percent of the adolescents (versus $32 \%$ of the adults, $\mathrm{p}<0.001$ ) used some contraceptive method before gestation; no adolescent and only one adult was a smoker. Pregnancy was not planned in $50 \%$ of the adolescents and in $35 \%$ of the adults $(\mathrm{p}=0.04)$. A mean of six pre-natal consultations was observed in both groups.

The overall prevalence of all the obstetric complications in pregnant teenagers was $45 \%$, with the most frequent being cephalopelvic disproportion $(10 \%)$, functional dystocia $(9 \%)$, premature rupture of membrane $(6 \%)$, and pre-eclampsia $(4 \%)$. The rate of cesarean deliveries among adolescents was $45 \%$. The frequency of these complications, together or alone, was similar to that presented by the adult group of pregnant women (Table 3). Multiple logistic regression

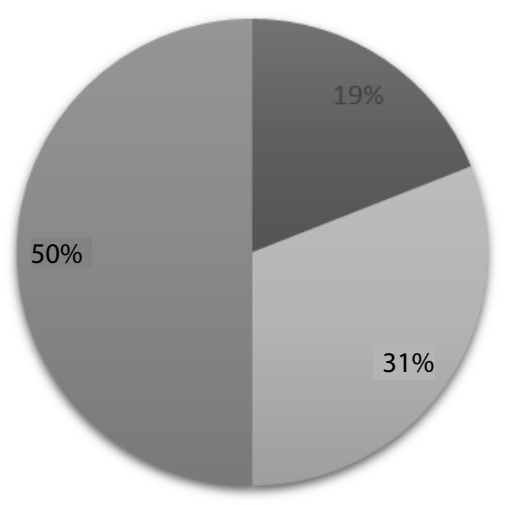

- Age group $<16$ Age group 16-17 - $\quad$ Age group 18-19

Figure 1: Distribution of pregnant adolescents by age group

\begin{tabular}{|c|c|c|c|}
\hline Variable & $\begin{array}{c}\text { Adolescents } \\
\text { N or mean (SD) }\end{array}$ & $\begin{array}{c}\text { Adults } \\
\text { N or mean (SD) }\end{array}$ & $\mathbf{p}$ \\
\hline Age (years) & $17.15(1.66)$ & $30.39(5.33)$ & 0 \\
\hline Height (centimeters) & $158.67(7.80)$ & $161.95(7.97)$ & 0 \\
\hline Weight (kg) & $56.73(9.59)$ & $65.32(10.88)$ & 0 \\
\hline BMI (kg/m2) & $22.58(3.8)$ & $24.89(3.7)$ & 0 \\
\hline Family Income** & $1.23(0.51)$ & $1.41(0.69)$ & 0.04 \\
\hline Marital Status & & & 0 \\
\hline Single & 50 & 30 & \\
\hline Married & 6 & 41 & \\
\hline Consensual Union & 44 & 29 & \\
\hline Color (Self-reported) & & & \\
\hline White & 3 & 97 & 0.14 \\
\hline Mulatto and Black & 97 & & \\
\hline Education level & & 3 & \\
\hline$\leq 4$ years & 10 & 93 & \\
\hline 5 - 11 years & 90 & & \\
\hline$\geq 12$ years & 0 & & \\
\hline
\end{tabular}

*BMI: Median of 23.3 and $25 \%$ interquartile ranging from 20.5 to 26.2 . ${ }^{* *}$ Brazilian minimum wages (approximately USD 315.00 )

Table 1: Sociodemographic characteristics of adolescents and adults pregnant women. 


\begin{tabular}{|c|c|c|c|}
\hline Variable & $\begin{array}{c}\text { Adolescents (N=100) } \\
\text { N or mean (SD) }\end{array}$ & $\begin{array}{c}\text { Adults (N=100) } \\
\text { N or mean (SD) }\end{array}$ & $\mathbf{p}$ \\
\hline Age of menarche (years) & $12.72(1.42)$ & $12.89(1.51)$ & 0.41 \\
\hline $\begin{array}{c}\text { Beginning of sexual life } \\
\text { (years) }\end{array}$ & $15.07(1.49)$ & $18.44(3.52)$ & 0.00 \\
\hline $\begin{array}{c}\text { Age at first pregnancy } \\
\text { (years) }\end{array}$ & $16.26(1.78)$ & $23.15(5.00)$ & 0.00 \\
\hline Gynecological Age (years) & $3.54(1.66)$ & $10.26(5.04)$ & 0.00 \\
\hline Partners & $1.93(1.33)$ & $1.82(1.05)$ & 0.52 \\
\hline Pregnancies & $1.26(0.56)$ & $2.74(1.69)$ & 0.00 \\
\hline Abortions & $0.12(0.33)$ & $0.46(0.69)$ & 0.00 \\
\hline Pre-Natal Consultations & $6.01(1.81)$ & $6.26(2.24)$ & 0.39 \\
\hline Smoking (No) & 100 & 99 & 1.00 \\
\hline Alcoholism (No) & 99 & 97 & 0.62 \\
\hline Drugs (No) & 100 & 99 & 1.00 \\
\hline Used CM (yes) & 12 & 32 & 0.00 \\
\hline Planned pregnancy & 50 & 65 & 0.04 \\
\hline
\end{tabular}

SD: Standard deviation, No.: Number, CM: contraceptive method

Table 2: Clinical characteristics of adolescents and adults pregnant women.

analysis determined that no variables were significantly associated with high risk of complications in teenage pregnancy.

The negative outcomes that most frequently affected the newborn infants of adolescent mothers were acute fetal suffering (7\%), LBW (6\%), overweight (2\%), prematurity (1\%), (Table 3). The Apgar score in these NB was 8.22 in the first and 9.01 in the fifth minute. None of these outcomes differed statistically when compared with the NB in the group of adults. The only exception was for a lower weight observed between the newborn of adolescents (adolescent group: $3,119 \pm 434 \mathrm{~g} v \mathrm{~s}$. adult group: 3,271 $\pm 395 \mathrm{~g}, \mathrm{p}=0.01$ ) (Table 3).

The serologies for rubella, toxoplasmosis, cytomegalovirus, HIV, HTLV and VDRL were negative for all the pregnant women. The laboratory exams were normal and the serologies negative (data not shown).

\section{Discussion}

In the present study, it was observed that pregnancy in adolescence was not associated with unfavorable peri-natal or obstetric results when compared with those of adult pregnant women. However, a strongly positive association was observed between teenage pregnancy and social vulnerability. The low incidence of adverse peri-natal and maternal effects could be more correlated to adequate pre-natal care than to the mother's age. Indeed, all the women in the present study had adequate pre-natal care, including at least six consultations, complementary exams and regular multidisciplinary follow-up in the Family Health Program. Pre-natal care is widely recognized as one of the main determinants of health gestational development. According to the integral care program for women's health of Brazilian Ministry of Health [13], adequate pre-natal care should guarantee a minimum of six consultations, early beginning of pre-natal care ( $<12$ weeks) and having the complete set of exams requested. This was observed in both groups in the present study, irrespective of age group.

The only statistically different clinical outcome between the two groups was neonatal weight, which was lower in the group of adolescents. However, without clinical significance, since it did not present LBW (defined as NB weight $<2,500 \mathrm{~g}$ ). LBW is considered an indicator of the population's conditions of health, because it is the most important determinant of the newborn's chance to survive and present satisfactory growth and development [14]. The prevalence of LBW recorded in the group of adolescents was 7\%, and is one of the lowest recorded in developing countries. Mesleh et al. in Arabia, found an incidence of $21.5 \%$ of LBW in adolescents [15], while Kumbi and Isehak verified $27 \%$ of LBW among adolescents in Ethiopia [16]. In Brazil, a previous study observed an incidence of $12.8 \%$ of LBW in newborn of teenage adolescents in Rio de Janeiro [17]. A higher risk for LBW is particularly important among socially vulnerable adolescent mothers (without partner), smokers and absence of pre-natal care [18].

The low incidence of LBW in the present study may be due to the absence of smoker pregnant women, and adequate pre-natal care followup. An important population-based study conducted in Latin America with 854,377 women under 25 years of age observed a higher incidence of adverse peri-natal effects among the adolescents, particularly among those in early adolescence ( $\leq 15$ years of age), such as LBW and prematurity [19]. In the present study, the mean age of the group of adolescents was 17 years, indicating that LBW might be less frequent in pregnancy in late adolescence. A relevant aspect found in the present study was the higher social risk for pregnant teenagers. Compared with the group of adult pregnant women, half of the adolescents were single, only $45 \%$ lived with a partner and had a lower family income. A Meta-analysis conducted by Imamura et al. demonstrates consistent association between social inequalities and gestation in adolescence in European countries [20]. Similarly, a study conducted in 645 municipalities in the State of São Paulo in Brazil, demonstrated a close association between teenage pregnancy and economic and social indicators. The percentage of pregnancy in adolescence was shown to be higher in the municipalities with lower Gross National Product, higher incidence of poverty, smaller population size and higher percentage of individuals more vulnerable to poverty [21]. The age of beginning with sexual life and gynecological age were lower in the group of adolescents. Previous studies have demonstrated that early beginning of sexual activity is a risk factor for pregnancy in adolescence [22]. Half of the adolescents interviewed in the present study did not plan the pregnancy. International literature indicates that over half of

\begin{tabular}{|c|c|c|c|}
\hline Complications & $\begin{array}{c}\text { Adolescents } \\
\mathrm{N} \text { or mean (SD) }\end{array}$ & $\begin{array}{c}\text { Adults } \\
\mathrm{N} \text { or mean (SD) }\end{array}$ & $\mathbf{p}$ \\
\hline Total & 45 & 43 & 0.89 \\
\hline PROM & 6 & 3 & 0.49 \\
\hline RIUG & 1 & 0 & 1.00 \\
\hline $\begin{array}{l}\text { Cephalopelvic } \\
\text { disproportion }\end{array}$ & 10 & 12 & 0.82 \\
\hline Pre-eclampsia & 4 & 3 & 1.00 \\
\hline $\begin{array}{l}\text { Functional } \\
\text { dystocia }\end{array}$ & 9 & 13 & 0.49 \\
\hline Oligohydramnios & 0 & 3 & 0.24 \\
\hline $\begin{array}{l}\text { Cesarean } \\
\text { delivery* }\end{array}$ & 45 & 54 & 0.25 \\
\hline $\begin{array}{l}\text { Acute fetal } \\
\text { suffering }\end{array}$ & 6 & 4 & 0.74 \\
\hline Low Birth Weight & 7 & 2 & 0.17 \\
\hline Prematurity & 4 & 0 & 0.14 \\
\hline $\begin{array}{l}\text { Fetal weight } \\
\text { (grams) }\end{array}$ & $\begin{array}{l}3,119.8 \\
(434.8)\end{array}$ & $\begin{array}{l}3,271.4 \\
(395.5)\end{array}$ & 0.01 \\
\hline $\begin{array}{l}\text { Apgar in 1st } \\
\text { minute }\end{array}$ & $8.22(0.93)$ & $8.46(0.64)$ & 0.24 \\
\hline $\begin{array}{l}\text { Apgar in 5th } \\
\text { minute }\end{array}$ & $9.01(0.52)$ & $9.08(0.58)$ & 0.07 \\
\hline
\end{tabular}

RIUG: Retarded Intrauterine Growth, PROM: Premature Rupture of Membrane * Eight pregnant women had two unfavorable outcomes simultaneously

Table 3: Distribution of maternal-fetal complications evaluated in pregnant adolescent and adult women. 
the adolescents do not plan the pregnancy and over $90 \%$ do not desire the pregnancy [23]. The lower frequency of unplanned pregnancy in our study may be justified by the inclusion of pregnant adolescents who began with pre-natal care, excluding those who terminated the pregnancy by induced or spontaneous abortion [24,25]. Furthermore, the GRAVAD study conducted in three Brazilian capitals, with 4,634 individuals (between 18 and 24 years of age) demonstrated that for the majority of youngster in the poorer social segments, without academic or professional perspectives, maternity (or paternity) is seen as a sign of social status [26]. In addition, in this same cohort another study found a positive association between the mother's age at her first pregnancy and her daughter's at first pregnancy experience [27]. A study conducted in Turkey found that pregnant teenagers were less educated adolescents, who are subject to intimate partner violence and were married to less educated partners [28].

An important limitation of our study was the low number (11\%) of individuals in early adolescence. These face substantially greater risks of maternal and peri-natal morbimortality than the groups of individuals in late adolescence [19]. Additionally, the high number of prenatal visit (six visits per adolescent) might have an impact to minimize unfavorable pregnancy outcomes observed in the present study. It is well known that maternal morbidity is associated with a low number of prenatal consultations [29].

In conclusion, in spite of there having been no evidence of biologic risk for adolescents and their NB, greater social risk was observed in the present study. The adolescents presented low income, higher number of sexual partners and less information about contraceptive methods. Therefore, future research is needed to search access to health services for women in this age-range and prevent the high unplanned adolescents' pregnancy rates. Social programs are important too by means of support networks, including the families and health and educational services, especially for adolescents who are unable to rely on a stable family structure. Investment in the health of women and children, including their permanence at school, delaying the first pregnancy, may contribute to the economic development of a nation [30].

\section{Acknowledgements}

We are grateful to all the young persons who participated in the study and to the nurses of Family Health Program for the excellent care given to our subjects. This paper is part of TSM's PhD. Thesis of the Bahiana School of Medicine and Public Health Post Graduate Course.

\section{References}

1. World Health Organization (1975). International classification of diseases. 9th revision. Geneva: WHO Library.

2. Alan Guttmacher Institute (2013) U.S. Teenage Pregnancies, Births and Abortions, 2008: State Trends by Age, Race and Ethnicity. New York, NY: Alan Guttmacher Institute

3. World Health Organization (1998) The World Health Report 1998. Life in the 21st century: a vision for all. Geneva: WHO. p. 97.

4. Instituto Brasileiro de Geografia e Estatística (IBGE). Síntese de indicadores sociais: 2010. Rio de Janeiro: IBGE; 2010. (Estudos e pesquisas: informação demográfica e socioeconômica.

5. Pesquisa Nacional de Demografia e Saúde da Criança e Mulher (PNDS), 2006

6. Goldenberg RL, Culhane JF, lams JD, Romero R (2008) Epidemiology and causes of preterm birth. Lancet 371: 75-84.

7. dos Santos GH, Martins Mda G, Sousa Mda S (2008) Teenage pregnancy and factors associated with low birth weight. Rev Bras Ginecol Obstet 30: 224-231.

8. Conde-Agudelo A, Belizán JM, Lammers C (2005) Maternal-perinatal morbidity and mortality associated with adolescent pregnancy in Latin America: Crosssectional study. Am J Obstet Gynecol 192: 342-349.

9. Klein JD (2005) American Academy of Pediatrics Committee on Adolescence (2005) Adolescent pregnancy: current trends and issues. Pediatrics 116: 281 286

10. Kassar SB, Gurgel RQ, Alburquerque MFM, Barbieri MA, Lima MC (2006) Comparações das condições socioeconômicas e reprodutivas entre mães adolescentes e adultas jovens em três maternidades públicas de Maceió. Rev. Bras. Saúde Materno Infantil 6: 397-403

11. The Alan Guttmacher Institute (2011) Issues in brief: risks and realities of early childbearing worldwide. New York: The Alan Guttmacher Institute; 1997. p. 1-3. Fundação Internacional de Desenvolvimento Agricola.

12. Pirovano G, Nodari R (1965) Values and limits of the Apgar index. Minerva Pediatr 17: 1703-1705

13. Ministry of Health of Brazil. National Policy for Integral Attention to Women's Health 2007

14. Murata MK, Schimarelli GT, Sfendrych RR, Yones PA, Ceccatto VP et al. (1998) Gravidez na adolescência: estudo epidemiológico no Hospital Evangélico de Curitiba. ACM Arq Catarin Med 27: 19-24.

15. Mesleh RA, Al-Aql AS, Kurdi AM (2001) Teenage pregnancy. Saudi Med J 22 864-867.

16. Kumbi S, Isehak A (1999) Obstetric outcome of teenage pregnancy in northwestern Ethiopia. East Afr Med J 76: 138-140

17. Gama SGN, Szwaarwald CL, Leal MC, Thene Filha MM (2001) Gravidez na adolescência como fator de risco para baixo peso ao nascer no município do Rio de Janeiro: 1996 a 1998. Revista de Saúde Pública 35: 74-80.

18. Guimarães AM, Bettiol H, Souza Ld, Gurgel RQ, Almeida ML, et al. (2013) Is adolescent pregnancy a risk factor for low birth weight? Rev Saude Publica 47: 11-19.

19. Conde-Agudelo A, Belizán JM, Lammers C (2005) Maternal-perinatal morbidity and mortality associated with adolescent pregnancy in Latin America: Crosssectional study. Am J Obstet Gynecol 192: 342-349.

20. Imamura M, Tucker J, Hannaford P, da Silva MO, Astin M, et al. (2007) Factors associated with teenage pregnancy in the European Union countries: a systematic review. Eur J Public Health 17: 630-636.

21. Martinez EZ, Roza DL, Caccia-Bava Mdo C, Achcar JA, Dal-Fabbro AL (2011) Teenage pregnancy rates and socioeconomic characteristics of municipalities in São Paulo State, Southeast Brazil: a spatial analysis. Cad Saude Publica 27: 855-867.

22. Wellings $K$, Nanchahal K, Macdowall W, McManus S, Erens B, et al. (2001) Sexual behaviour in Britain: early heterosexual experience. Lancet 358: 18431850.

23. Finer LB, Zolna MR (2011) Unintended pregnancy in the United States: incidence and disparities, 2006. Contraception 84: 478-485.

24. Zabin LS, Kiragu K (1998) The health consequences of adolescent sexual and fertility behavior in sub-Saharan Africa. Stud Fam Plann 29: 210-232.

25. Alan Guttmacher Institute (2002) Teen pregnancy: trends and lessons learned

26. Heilborn ML, Cabral CS (2011) A new look at teenage pregnancy in Brazil ISRN Obstet Gynecol 2011: 975234.

27. de Almeida Mda C1, Aquino EM (2009) The role of education level in the intergenerational pattern of adolescent pregnancy in Brazil. Int Perspect Sex Reprod Health 35: 139-146.

28. Edirne T, Can M, Kolusari A, Yildizhan R, Adali E, et al. (2010) Trends, characteristics, and outcomes of adolescent pregnancy in eastern Turkey. Int $J$ Gynaecol Obstet 110: 105-108.

29. Morse ML, Fonseca SC, Gottgtroy CL, Waldmann CS, Gueller E (2011) Severe maternal morbidity and near misses in a regional reference hospital. Rev Bras Epidemiol 14: 310-322.

30. Stenberg K, Axelson H, Sheehan P, Anderson I, Gülmezoglu AM, et al. (2014) Advancing social and economic development by investing in women's and children's health: a new Global Investment Framework. Lancet 383: 1333-1354. 